\title{
RECENSIONES
}

\section{La invalidez sobrevenida de los actos jurídicos: inconstitucionalidad sobrevenida e invalidez sobrevenida de los actos administrativos}

\author{
Juan Manuel Alegre Ávila \\ Catedrático de Derecho Administrativo \\ de la Universidad de Cantabria \\ Exletrado del Tribunal Constitucional
}

I. UNAS PINCELADAS SOBRE LA INCONSTITUCIONALIDAD DE LAS LEYES: LA LLAMADA INCONSTITUGIONALIDAD SOBREVENIDA

1. Las leyes preconstitucionales contrarias a la Constitución: ¿derogación o inconstitucionalidad? La Disposición derogatoria única. 3 de la Constitución y la dualidad del control jurisdiccional.

La Disposición derogatoria única.3 de la Constitución de 1978 declara derogadas las normas que se opusieren a lo en ella dispuesto. A esta peculiar derogación ha dado en llamarse "inconstitucionalidad sobrevenida", cuya constatación, vale decir el control de las leyes preconstitucionales, no es asumida en régimen de monopolio por el Tribunal Constitucional, que desde su Sentencia 4/1981 ha venido considerando (SSTC 126/1997, 159/2001) que tanto la jurisdicción constitucional como la jurisdicción ordinaria tienen competencia para apreciar aquella derogación, la primera en virtud de la incompatibilidad con la Constitución, norma suprema del ordenamiento jurídico, de las normas con rango de ley (siquiera éstas fueran promulgadas bajo el sistema de fuentes anterior al inaugurado por el texto de 27 de diciembre de 1978), la segunda por el carácter de norma posterior de la Constitución, que, en este razonamiento, habría producido la derogación, esto es, la pérdida de vigencia de las normas anteriores cuyo contenido resulte opuesto al de aquélla (artículo 2.2, primera 
proposición, del Código Civil). De acuerdo a este planteamiento, por tanto, el fenómeno de las leyes preconstitucionales contrarias a la Constitución se ofrece bajo una doble faz, una cuestión de incompatibilidad con norma superior (y suprema), esto es, un problema de constitucionalidad, de un lado; y un supuesto de derogación o vigencia, en tanto que problema atinente a la sucesión de normas (incompatibles) en el tiempo. Aquélla justifica la competencia de la jurisdicción constitucional, ésta, la de la jurisdicción ordinaria.

Las consecuencias de esta dualidad jurisdiccional son de fácil advertencia: mientras los pronunciamientos del Tribunal Constitucional, por su eficacia erga omnes, provocan la expulsión del ordenamiento de las leyes contrarias a la Constitución, las singulares (y eventualmente contradictorias) decisiones de los órganos judiciales no tienen otro efecto que el desplazamiento en el oportuno proceso judicial de la ley preconstitucional tachada de inconstitucional en tanto que inaplicable por pérdida de vigencia (recte: por haber quedado -tácitamente- drogada).

\section{Derogación expresa y derogación tácita: fundamento y conse- cuencias.}

Conviene, pues, inquirir el fundamento de esta afirmada dualidad jurisdiccional. Su identificación permitirá dar cuenta de la bondad de la solución avalada por el Tribunal Constitucional, mas también, en un orden ajeno al sistema de fuentes, pero partícipe de la teoría de la validez de los actos jurídicos en un sentido amplio, del canon dogmático que permita enjuiciar con la debida propiedad la razón de la no pervivencia de los actos administrativos por desaparición de la norma de cobertura.

A) A este propósito ya se ha adelantado el juego del binomio inconstitucionalidad/derogación y su trasunto jurisdiccional, la competencia del Tribunal Constitucional junto a la del Poder Judicial. Un binomio que se hace derivar de la dual consideración de la Constitución, norma superior y norma posterior, que permite dar cuenta de este peculiar fenómeno signado como "inconstitucionalidad sobrevenida". Precisamente es la singularidad de la norma de contraste, la Constitución, la que, en la lógica del argumento precedente, justifica la competencia del Tribunal Constitucional, una competencia, ya se ha dicho, que deriva del peculiar vicio de la ley preconstitucional, que permite tachar a ésta de inconstitucional por razones sobrevenidas (la aparición de la Constitución). De este modo, eta competencia y este vicio al que ha dado en llamarse "inconstitucionalidad sobrevenida" jugarían, en la economía del sistema, a modo de excepción, pues el principio general vendría a ser la mera pérdida de vigen- 
cia de la ley preconstitucional por incompatibilidad con una norma (de rango superior, pero esto es indiferente ahora) posterior. Incompatibilidad a la que habría que anudar la oportuna consecuencia, a saber, la derogación de la norma anterior e incompatible con la posterior, mas una derogación tácita o implícita, puesto que el número 3 de la Disposición derogatoria única de la Constitución de 1978 no contiene un elenco, nominatim, de las normas que deroga (a diferencia de lo consignado en los precedentes apartados 1 y 2), al limitarse a dejar constancia de aquel efecto respecto de "cuantas disposiciones se opongan a lo establecido en esta Constitución".

Así pues, habrá que discernir el sentido y el alcance de la llamada derogación tácita por contraste u oposición con los efectos que despliega la derogación expresa.

B) Este par de conceptos, expreso/tácito, reclama, aun cuando no sea simétrico, de otro binomio, validez/eficacia. El segundo término de este último es, justamente, el que permite dar cuenta del sentido y alcance del primer binomio, en la medida en que la explicación del fenómeno de la derogación tácita ha de hacerse a partir de la distinción entre validez y eficacia. Una distinción que, en otro orden de ideas, como arriba quedó apuntado, es el que debe operar a la hora de dar cuenta de la desaparición de la cobertura normativa de los actos administrativos, supuesto que, a su vez, hace entrar en escena otro par de conceptos, los de anulación/revocación. Fenómeno este último, el de la pérdida de cobertura de los actos dictados al amparo de una determinada normativa, que últimamente ha tratado de explicarse al socaire de la noción de invalidez sobrevenida, y que, más allá del oxímoron que expresa, se sitúa en la estela de la inconstitucionalidad sobrevenida, que es el objeto primario de nuestra atención. Una noción, como tratará de argumentarse, no sólo conceptualmente errónea sino, además, innecesaria. Vayamos por partes ${ }^{1}$.

\footnotetext{
${ }^{1}$ Las consideraciones que siguen son tributarias del, importante, sin duda, libro de Luis María DíezPicazo Jiménez La derogación de las leyes, prólogo de Francisco Rubio Llorente, Civitas, Madrid, 1990. Su análisis del fundamento y los efectos de la derogación expresa [107 ss.] y de la derogación tácita [285 ss.], con particular referencia a la llamada inconstitucionalidad sobrevenida [305 ss.], me parece sencillamente modélico. La apropiación, mejor, aprovechamiento, de las ideas de este autor no es óbice para que, eventualmente, ante esta confesión, pueda tacharse de incoherente lo que se dice en el texto de resultas del juicio de contraste con las tesis de Díez-Picazo Jiménez. Esta "incoherencia” es, dicho sea crudamente, dolosa, conscientemente querida, y, por tanto, expresiva, caso de producirse, de una discrepancia con aquellas tesis, vale decir reflejo de mi entendimiento de la aplicación de las categorías concernidas a la cuestión examinada.
} 
C) La derogación expresa (que refleja el brocardo lex posterior derogat legem anteriorem) remite a una cuestión de vigencia. La norma (expresamente) derogada pierde vigencia porque desaparece. En consecuencia, y como señala la última proposición del artículo 2.2 del Código Civil ("Por la simple derogación de una ley no recobran vigencia las que ésta hubiere derogado"), la derogación de la norma derogatoria no implica, por sí sola, la recuperación de la vigencia de la norma derogada, esto es, dicho en términos organicistas, la resurrección o restauración (más que restauración o rehabilitación, una verdadera y propia reconstrucción) de esta última, justamente porque el efecto anudado a la derogación expresa es la supresión o eliminación como producto jurídico de la norma derogada.

Una matización a propósito del alcance de la citada última proposición del artículo 2.2 del Código Civil. La consecuencia en aquella formulada tiene un campo de aplicación nítidamente delimitado: la no recuperación de la vigencia a que la misma se refiere alcanza al supuesto de que la norma que deroga a la anterior norma derogatoria no haya expresamente dispuesto nada en relación a la norma por esta última derogada. Nada impide, pues, que la recuperación de la vigencia de la norma inicialmente derogada se produzca en virtud de una llamada expresa de la última norma (la derogatoria de la derogatoria, valga el retruécano), pero en este caso no hay propiamente una recuperación de la vigencia de la norma en cuestión, sino, en puridad, una nueva norma cuyo contenido coincide con el texto de la que fue en su momento derogada, siquiera esta nueva norma se exprese formalmente en virtud de la recepción de aquel contenido textual por la última norma. La derogación expresa, en cuanto provoca la pérdida de vigencia de la norma derogada, no admite, en consecuencia, la resurrección de lo que desapareció como producto normativo.

D) La derogación tácita (o implícita: hagamos sinónimos ambos términos), en cambio, no hace referencia a una cuestión de vigencia, sino, como dice la segunda proposición del artículo 2.2 del Código Civil ["La derogación tendrá el alcance que expresamente se disponga y se extenderá siempre a todo aquello que en la ley nueva, sobre la misma materia, sea incompatible con la anterior"], a una de compatibilidad entre dos normas. De ahí que el efecto provocado por la posterior no diga relación con la pérdida de vigencia de la anterior, sino con la pérdida de eficacia, esto es, la no susceptibilidad o falta de idoneidad de esta última (obviamente, por razones sobrevenidas, como es meridiano: nos movemos en el ámbito de la sucesión de normas en el tiempo) para regular (eficazmente, esto es, con pretensión normativa de disciplina de una determinada realidad) el supuesto de hecho considerado. Esta pérdida de eficacia (normativa) se traduce, en consecuencia, en un fenómeno de desplazamiento de la norma anterior, cuyo espacio pasa a ser ocupado por la nueva norma con un carácter 
de preclusión o cierre. Esta expulsión, que no desaparición o eliminación, de la norma anterior puede gráficamente describirse con los términos congelación o hibernación, o, por utilizar una categoría de reciente predicamento, empleada, por ejemplo, por el Tribunal Constitucional español para explicar las relaciones entre el Derecho interno y el Derecho comunitario europeo, primacía: la norma posterior prima, desplazándola, sobre la norma anterior, y ello, y esto es lo que importa retener, aun en la hipótesis de que aquélla, la norma posterior, tenga un rango o valor superior a ésta, la norma anterior (así, ley-reglamento o Constitución-ley)².

\section{La llamada inconstitucionalidad sobrevenida como un supuesto de derogación tácita: pérdida de eficacia de la ley preconsti- tucional y justificación del control por la jurisdicción consti- tucional.}

La cuestión del rango normativo a que se alude en el cierre del epígrafe anterior es el factor que puede haber inducido la disputa doctrinal acerca del problema concernido, si inconstitucionalidad o derogación, y, de resultas, la controversia sobre la jurisdicción competente para elucidar la contradicción entre una ley anterior a la Constitución y esta última. No hay, como acaba de decirse, una diversidad sustantiva en cuanto al problema analizado por razón de que la norma de contraste sea de rango superior a la que entra en colisión con aquélla, pues el fenómeno es único, a saber, la derogación tácita de la norma anterior por incompatibilidad con la norma posterior. Puede aceptarse una peculiaridad que modula la solución al problema suscitado, derivada de que la norma de contraste es, justamente, la norma suprema del ordenamiento jurídico, la Constitución, una peculiaridad o modulación que, en todo caso, no atañe a la caracterización del problema, sino a la determinación de la jurisdicción encargada de dilucidar la eventual incompatibilidad entre la ley preconstitucional y la Constitución.

En esta tesitura, por tanto, la dualidad jurisdiccional (Tribunal Constitucional/Poder Judicial) no dimana de que la cuestión implicada revista un carácter dual, inconstitucionalidad (motejada, para salvar la coherencia del argumento, de sobrevenida)/derogación, cuestión cuyos contornos son unitarios, la aludi-

\footnotetext{
${ }^{2}$ La cuestión del rango normativo sólo entra en juego, como es claro, cuando se trata de normas producidas en el mismo ordenamiento jurídico, no cuando se trata de normas procedentes de diferentes ordenamientos jurídicos. Así, esta noción de primacía es la que permite dar cuenta de las relaciones entre los Tratados internacionales y las leyes internas o, específicamente, de las que median entre el Derecho comunitario europeo y los derechos internos.
} 
da derogación por incompatibilidad, sino por la presencia, como parámetro de esa incompatibilidad, de la Constitución, que parece reclamar la intervención del Tribunal Constitucional, siquiera por razón de la certeza que deriva de aquella intervención, la declaración formal y solemne de que una ley preconstitucional ha devenido ineficaz para regular un determinado supuesto de hecho, dada su incompatibilidad con la norma suprema del ordenamiento jurídico. El sintagma inconstitucionalidad sobrevenida no es, por tanto, sino un mero nomen que apela a una cuestión jurisdiccional, la conveniencia de la intervención del Tribunal Constitucional, y no a un problema dogmático cuyo polos vendrían representados por los términos inconstitucionalidad y derogación.

\section{LA INCONSTITUCIONALIDAD SOBREVENIDA Y SU PRO- YEGGIÓN EN EL DEREGHO ADMINISTRATIVO: LA LLA- MADA INVALIDEZ SOBREVENIDA DE LOS ACTOS ADMI- NISTRATIVOS}

\section{La teoría de la invalidez sobrevenida de los actos administra- tivos en la reciente doctrina: la tesis de Tomás Cano Campos.}

La invalidez sobrevenida de los actos administrativos es el título de un libro de Tomás Cano Campos que viera la luz en $2005^{3}$. El sintagma invalidez sobrevenida, inevitablemente, ha de considerarse parónimo del antes analizado inconstitucionalidad sobrevenida, en cuanto ambos describen contenidos contiguos, si bien dicha contigüidad, en este último caso, apele a la confrontación entre normas de rango diferente, en los términos señalados, y, en el primero, diga relación con la desaparición de la cobertura normativa de un mero acto administrativo. En todo caso, el propósito perseguido con la construcción de esta categoría estriba en aglutinar, "exclusivamente desde un punto de vista puramente cronológico o temporal", aquellos supuestos en los que "la causa determinante de la invalidez del acto sea posterior al momento en que el mismo se dictó" 4 . Supuestos que Cano Campos sintetiza del modo que sigue.

Así, en primer lugar, "la invalidez sobrevenida puede deberse a la aprobación de normas retroactivas que determinan la invalidez del acto a partir de un momento posterior a la emanación del mismo, o bien a la declaración de nu-

\footnotetext{
3 Tomás Cano Campos, La invalidez sobrevenida de los actos administrativos, prólogo de Eduardo García de Enterría, Thomson-Civitas, Cizur Menor (Navarra), 2005.

4225.
} 
lidad de normas anteriores con base en las cuales el acto fue dictado y cuya invalidez, como consecuencia de aquella declaración, también tiene lugar a partir de un momento posterior al dictado del acto" 5 .

En segundo lugar, "la invalidez sobrevenida puede producirse cuando tiene lugar la pérdida de alguno de los requisitos objetivos de validez del acto, siempre, claro está, que el ordenamiento exija que tales requisitos hayan de permanecer durante toda la «vida» del acto o hasta un momento posterior a su emanación”. En consecuencia, se pregunta el referido autor, “¿cuáles son tales requisitos de validez del acto que pueden desaparecer de forma sobrevenida y dan lugar a este tipo de invalidez?". Respuesta: "No son otros que algunos de los denominados elementos del acto", en tanto que "los elementos de los actos administrativos constituyen auténticos requisitos de validez de los mismos, cuyo examen sirve para precisar las exigencias que tales actos deben cumplir para ser válidos o conformes a Derecho"6.

A este ensayo de clasificación sigue el análisis de los distintos supuestos individualizados de invalidez sobrevenida. Así, los aglutinados en torno a la aprobación de normas retroactivas ${ }^{7}$; la anulación de la norma de cobertura de los actos administrativos ${ }^{8}$; la desaparición del presupuesto de hecho o pérdida sobrevenida de la adecuación del acto al supuesto de hecho previsto en la norma9; la desaparición de la causa o desaparición sobrevenida de la adecuación del acto al fin previsto en la norma ${ }^{10}$; y, finalmente, la ilicitud e imposibilidad sobrevenida del contenido del acto ${ }^{11}$. El estudio concluye con el examen de las consecuencias anudadas a los supuestos de invalidez sobrevenida y de los instrumentos previstos para hacer frente a los mismos, postulando la necesidad de una regulación general de la invalidez sobrevenida, de resultas de la insuficiencia de los instrumentos, tanto de los contemplados en la legislación sectorial, como de los generales de la Ley 30/1992, esto es, la nulidad y la anulabilidad, que el ordenamiento actual prevé como mecanismos de reacción en estos casos ${ }^{12}$.

\footnotetext{
5242.

6 242-43.

7244 ss.

${ }^{8} 261$ ss.

${ }^{9} 279$ ss.

10293 ss.

11307 ss.

12313 ss., en particular, 363 ss.
} 


\section{La invalidez sobrevenida a la luz de la teoría del acto admi- nistrativo: crítica.}

A) El encuadramiento de esta problemática pasa por el recordatorio de las categorías generales de la teoría del acto administrativo, tal y como se configura en la Ley 30/1992, de 26 de noviembre, de Régimen Jurídico de las Administraciones Públicas y del Procedimiento Administrativo Común [en adelante, LRJ-PAC]. El punto de partida es, naturalmente, la caracterización del acto administrativo como declaración ejecutiva (artículo 56), Una ejecutividad que se desdobla en dos planos, a saber, la presunción de validez y la eficacia (artículos 57 y 93). Eficacia que, en el caso de los actos susceptibles de ejecución forzosa (artículos 95 y siguientes) recibe el específico nombre de ejecutoriedad (artículo 93).

B) Una caracterización, la así descrita, que apela a la fisiología o dinámica del acto administrativo y que, naturalmente, presupone la estructura o anatomía de aquél, tradicionalmente desglosada en la distinción entre elementos subjetivos, objetivos y formales. A su vez, contenido, causa y fin integran los elementos objetivos del acto administrativo, definiéndose la causa como la adecuación del contenido al fin (artículo 53.2), un fin que, en todo caso, ha de ser el específicamente previsto en la norma (principio de tipicidad, de donde el vicio de desviación de poder: artículos 63.1 LRJ-PAC y 70.2, párrafo segundo, de la Ley de la Jurisdicción Contencioso-Administrativa de 1998), y cuyo control se verifica mediante el de la motivación del acto (artículo 54 LRJ-PAC).

C) La patología del acto administrativo ${ }^{13}$ exige partir de estos tres pares de conceptos: anatomía/fisiología; validez/eficacia; anulación/revocación. Pares de conceptos que encuentran su hilo conductor en estas dos proposiciones, que de modo transversal recorren la lógica del acto administrativo en las dos vertientes, anatómica y fisiológica, apuntadas, a saber: una, la validez es el necesario punto de inserción del acto en la vida jurídica; dos, una vez producida es-

${ }^{13}$ La teoría del acto administrativo se ha construido, como es sabido, sobre dos planos o perspectivas, la del negocio jurídico y la de la resolución (sentencia) judicial. De acuerdo al primero el acto administrativo es una declaración, de voluntad, juicio, deseo o conocimiento, emanada de una Administración pública en ejercicio de una potestad administrativa [...distinta de la potestad reglamentaria, según la precisión que, en la definición clásica de Zanobini, introdujera García de Enterría]. La perspectiva procesal se asienta en la distinción sentencia declarativa/sentencia ejecutiva, cuyo correlato es el binomio (presunción de) validez/eficacia, trasunto de las dos manifestaciones de la autotutela administrativa, la declarativa y la ejecutiva. 
ta inserción, toda la dinámica del acto ha de enfocarse exclusivamente desde la perspectiva de la eficacia. Conceptos y proposiciones que constituyen, pues, la nervatura del argumento que a continuación se expone.

D) La construcción de Cano Campos, como la de Matilde Carlón Ruiz ${ }^{14}$, erigen la noción de validez en piedra ancilar de la subsistencia del acto administrativo en los supuestos al efecto singularizados, y arriba descritos [anulación de la norma de cobertura o aprobación de una norma retroactiva; cambio de la normativa reguladora que provoque ya una desaparición del presupuesto de hecho ya una modificación del contenido a que se contraiga el acto de referencia ya, finalmente, la del propio fin de éste, esto es, la, en la caracterización de este autor, desaparición sobrevenida de la causa], y cuyo nexo es la aparición de un hecho (normativo) que provoca un desajuste entre el acto y el nuevo estado de cosas surgido. Este desajuste, diacrónico, por tanto, es el que lleva a forzar la noción de validez para dar entrada a la (heterodoxa; un oxímoron, en definitiva) de "invalidez sobrevenida".

E) Recordemos un precepto, el artículo 16 de Reglamento de Servicios de las Corporaciones Locales de 17 de junio de 1955, que compendia las consecuencias anudadas a las autorizaciones o licencias expedidas por las Corporaciones Locales, en cuanto medio o técnica de intervención de la actividad de los administrados [artículo 5 b)] en los casos contemplados. Unas consecuencias que, y esto es lo que importa notar, apelan a la subsistencia de su eficacia, con independencia del concreto instrumento mediante el que se constate o declare la pérdida de efectos de la licencia otorgada. Dice así el referido artículo 16:

"1. Las licencias quedarán sin efecto si se incumplieren las condiciones a que estuvieren subordinadas, y deberán ser revocadas cuando desaparecieran las circunstancias que motivaron su otorgamiento o sobrevinieran otras que, de haber existido a la sazón, habrían justificado la denegación y podrán serlo cuando se adoptaren nuevos criterios de apreciación.

2. Podrán ser anuladas las licencias y restituidas las cosas al ser y estado primitivo cuando resultaren otorgadas erróneamente.

\footnotetext{
${ }^{14}$ Las autorizaciones industriales: un intento de aproximación sistemática, en Estudios de Derecho Público Económico. Libro Homenaje al Profesor Doctor don Sebastián MARTÍN-RETORTILLO, coordinación de Luis Cosculluela Montaner, Civitas, Madrid, 2003, 841 ss. El propio Tomás Cano, en este mismo volumen, ofrece un anticipo de sus tesis: La revocación de autorizaciones en el ámbito económico por razones de ilegalidad sobrevenida, 821 ss., en particular, 832 ss.
} 
3. La revocación fundada en la adopción de nuevos criterios de apreciación y anulación por la causa señalada en el párrafo anterior, comportarán el resarcimiento de los daños y perjuicios que se causaren".

Oportuno es, asimismo, recordar el texto del precedente artículo 15 en su apartado 1:

"1. Las licencias relativas a las condiciones de una obra o instalación tendrán vigencia mientras subsistan aquéllas".

F) El Reglamento de Servicios de 1955 es la norma que con carácter general (y abstracción hecha de que los supuestos codificados en sus artículos 15.1 y, sobre todo, 16 agoten, o no, el elenco de hipótesis que puedan englobarse en el rótulo "[pérdida de] eficacia") sitúa la técnica de la revocación como mecanismo de depuración de las consecuencias dimanantes del desajuste o falta de adecuación entre el acto administrativo, la licencia o autorización en el paradigma de la norma local, tal y como surge, en un momento determinado, a la vida jurídica, de un lado, y el estado (normativo) ulterior a que la evolución del ordenamiento pueda conducir, de otro, en cuanto el nuevo estado normativo se erige en parámetro de la (diacrónica, por definición) adecuación que se pretenda restablecer.

La revocación así concebida no es la que unos años más tarde regulará la Ley de Procedimiento Administrativo de 1958 en sus artículos 109 y siguientes, ni, por supuesto, la que hoy establece la LRJ-PAG en sus artículos 102 a 106 [ya en su versión inicial ya en la, simplificada, introducida por la Ley 4/1999]. Una revocación, la de las leyes de procedimiento, que lo es por motivos de legalidad, en cuanto técnica o mecanismo de verificación (de oficio) de la validez del acto. La anfibología o polisemia del término no ha confundido nunca a la doctrina, pero sí ha inducido los intentos de hacer pasar por el tamiz de la validez (de ahí la construcción que engloba el sintagma "invalidez sobrevenida") un variopinto elenco de supuestos que apelan a la eficacia del acto. Una eficacia que, ciertamente, deriva su razón de ser de la (presunción de) validez del acto, pero que va más allá, en tanto que aptitud o idoneidad del acto administrativo para modificar el estado de cosas preexistente y, singularmente, para ordenar las relaciones entre la Administración y el administrado. De ahí que cuando, en línea de principio, esta aptitud o idoneidad (el acto administrativo in acto, no meramente in potentia, esto es, la susceptibilidad anudada a la [presunción] de validez de aquél) entre en colisión con el nuevo estado de cosas (por definición, un estado normativo), éste demande, sin perjuicio del debido resarcimiento e indemnización (esto es indiferente en este momento), 
una labor de ajuste o adecuación, que, en el extremo, puede conducir a la desaparición, por ineficaz, del acto administrativo (entiéndase: desaparición del único vector estructural o arquitectural existente, o mejor, que permanece vigente, la eficacia). Una desaparición, o modulación de su pervivencia, a la que en puridad conviene el rótulo de revocación, categoría esta, por tanto, que adecuadamente da razón de la "resituación" del acto administrativo en el contexto de las circunstancias o hechos que conforman el ordenamiento jurídico en cada momento. Nada que ver, en suma, con un problema de validez, tal como pretende la doctrina que aquí se critica.

G) Volvamos la vista atrás y reparemos en los supuestos que registran los artículos 15.1 y 16 del Reglamento de Servicios de 1955: la pervivencia (recte: mantenimiento de vigencia, esto es, pervivencia o subsistencia ${ }^{15}$ ) de las licencias en tanto subsistan "las condiciones de una obra o instalación"; la pérdida de efectos por incumplimiento de las condiciones ${ }^{16}$ a que se subordinaren; la aparición o surgimiento de circunstancias que en su momento habrían determinado la denegación de la licencia; la adopción de nuevos criterios de apreciación; el otorgamiento erróneo.

Con la salvedad del último de los consignados, que apunta ("otorgamiento erróneo") a una defectuosa formación de la voluntad que expresa el acto en cuanto declaración susceptible, hoy, de ser tipificada como nula ex artículo

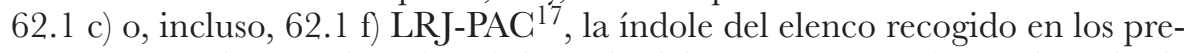
ceptos transcritos remite a la subsistencia del acto, esto es, a la pervivencia de sus efectos, vale decir mantenimiento (o modulación, según la intensidad del presupuesto de hecho en cada caso establecido) de la eficacia en el sentido antes apuntado, a saber, la aptitud o idoneidad del acto administrativo para or-

${ }^{15}$ La precisión, lingüística y conceptual, del Reglamento de Servicios es en algún caso susceptible de reproche, así, cuando en su artículo 11 dice que "serán ineficaces las nomas de las Ordenanzas y Reglamentos que contradijeren otras de superior jerarquía”. Salvo que se entienda que la contradicción lo es con norma posterior (supuesto en el que nos encontraríamos ante la llamada derogación tácita o implícita, de la que se ha hablado en el texto), esta "ineficacia" es, como fácilmente puede constatarse, invalidez. Este es, por lo demás, el sentido de este y similares preceptos (así, el artículo 51 LRJ-PAC).

16 "Condiciones" en el sentido de condicio iuris; no, por tanto, en la acepción estricta que, en el marco de los actos y contratos (si se prefiere, de la teoría del negocio jurídico), se anuda a la expresión en tanto que elementos accesorios de la declaración de voluntad.

17 Tipificación que demandaría la entrada en juego del procedimiento de revisión previsto en el artículo 102 LRJ-PAC, sin que, por tanto, dada la gravedad de la consecuencia, la anulación de la oportuna declaración, quepa subsumir el supuesto en el artículo 105.2 LRJ-PAC, que contempla el "error material, de hecho o aritmético". 
denar el concreto vínculo o relación surgido del otorgamiento de la licencia o autorización.

A mayor abundamiento, repárese en que nos hallamos en presencia de lo que, asimismo con un afán categorial, podemos denominar actos de tracto sucesivo (autorizaciones de actividad o de funcionamiento; rótulo en el que, sobre el modelo de la norma reglamentaria que nos ocupa, pueden englobarse los más variados supuestos previstos en la legislación sectorial: autorizaciones en los diferentes ámbitos de la actividad económica ${ }^{18}$, autorizaciones industriales ${ }^{19}$, de vertidos...), cuya esencia diacrónica es la que, justamente, se presta a albergar estos supuestos de desajuste o falta de adecuación entre el acto administrativo y el estado normativo resultante de los cambios o modificaciones que eventualmente pueden haber acaecido en el ordenamiento, aquellos en los que la dicotomía validez/eficacia permite dar cobijo, y hacerlo en la segunda de las nociones, a las consecuencias que dimanen de aquellos cambios o modificaciones.

\section{La reversión en la expropiación forzosa como supuesto de in- validez sobrevenida: crítica.}

A) Uno de los supuestos que Cano Campos engloba en su construcción de invalidez sobrevenida es el de la desaparición (sobrevenida) de la causa del acto administrativo, entendida aquélla como la falta de adecuación (sobrevenida) entre el contenido del acto y el fin normativamente previsto ${ }^{20}$. En particular, examina, dentro de la institución de la expropiación forzosa, la aplicación de esta teoría a la llamada causa expropiandi ${ }^{21}$, esto es, el juego de la reversión por desaparición sobrevenida de aquélla, según la caracterización al uso.

\footnotetext{
18 Tomás Cano Campos, La revocación de las autorizaciones en el ámbito económico por razones de ilegalidad sobrevenida, 821 ss. Autor que hace un repaso de los supuestos revocatorios que prevé nuestro Derecho, así, la revocación por razones de oportunidad [822-24], la revocación por razones de legalidad y de oportunidad [824-28], la revocación como actualización de las llamadas "cláusulas legales de revocación" [82831] o la revocación como instrumento para hacer valer la ilegalidad de los actos administrativos [831-32]. En el pórtico del examen de este último grupo de supuestos sostiene que "la relación en nuestro Derecho entre las figuras de la invalidez y de la revocación no es excluyente, como a veces se pretende, sino de instrumentalidad [sic]" [831]. Aserto que se pretende justificar en el uso indistinto que las leyes hacen de las expresiones "revisión" o "pérdida de vigencia" como sustitutas de la de "revocación", y que, en su opinión, permite "una explicación más certera o plausible de numerosos supuestos revocatorios previstos en el ámbito económico" [832]. Supuestos que, finalmente, hallan esa "explicación más certera o plausible" con la entrada en juego de la categoría de la... invalidez sobrevenida [832 ss.]

${ }^{19}$ Matilde Carlón Ruiz, Las autorizaciones industriales: un intento de aproximación sistemática, 841 ss., en particular, 859 ss.

${ }^{20}$ La invalidez sobrevenida de los actos administrativos, 293 ss.

${ }^{21}$ La invalidez sobrevenida de los actos administrativos, 295 ss.
} 
Pues bien, en un momento dado se detiene en el análisis y crítica de la concepción que de la causa expropiandi y, por ende, de la figura de la reversión expuse en mi trabajo El derecho de reversión en las expropiaciones legislativas. El caso $R u^{-}$ masa en la jurisprudencia del Tribunal Supremo ${ }^{22}$. Trabajo en el que sostenía que en la expropiación forzosa era menester diferenciar, como elementos objetivos del acto en que consiste la privación de la propiedad privada, la causa y el fin. Éste, el fin, debía localizarse en el artículo 9 de la Ley de Expropiación Forzosa de 1954, en tanto que aquélla, la causa, hallaba su ubicación en el artículo 15 de la referida, de donde la causa, en una concreta expropiación forzosa, venía identificada con el acuerdo de necesidad de ocupación, elemento objetivo, pues, del acto administrativo (artículos 53.2 LRJ-PAC y 6.1 del Reglamento de Servicios de 1955) en tanto que adecuación entre el contenido de la privación en que consiste la expropiación de un bien o derecho y el fin que justifica aquella privación. El corolario de este planteamiento es nítido, a saber, la reversión, en un sentido institucional, supone en una concreta expropiación la frustración del fin anudado a la privación en que aquélla se traduce, sin que, por tanto, deba conceptuarse, tal y como pretende la postura que en la expropiación forzosa identifica la causa y el fin, esto es, que hace equivalentes la causa expropiandi y el fin de la expropiación, la reversión o retrocesión como efecto subsiguiente a la desaparición sobrevenida de la causa expropiandi.

B) Esta tesis, que, como digo, partía de la distinción entre causa y fin en la institución de la expropiación forzosa, y que, sobre la base del triple nivel que la doctrina civilista ha identificado en la causa como elemento objetivo del ne-

${ }^{22}$ Juan Manuel Alegre Ávila, El derecho de reversión en las expropiaciones legislativas. El caso Rumasa en la jurisprudencia del Tribunal Supremo, "Revista de Administración Pública", 132, 1993, 229 ss. Las consideraciones que se hacen en el texto figuran, con unas u otrs palabras, en el prólogo que, por amable invitación de su autora, le puso al libro de Isabel Gallego Córcoles El derecho de reversión en la expropiación forzosa [La Ley, Las Rozas (Madrid), 2006, 23 ss.]. Séame permitido reproducir lo que decía en la primer página de aquel prólogo:

"A mediados de febrero de este año de 2006 se celebró en Toledo, con ocasión de su constitución, el Primer Congreso de la Asociación Española de Profesores de Derecho Administrativo. En su calidad de anfitriones, la intendencia corrió a cargo del grupo de jóvenes universitarios que dirige el profesor Luis Ortega Álvarez, entre los que se encontraba Isabel Gallego Córcoles, quien, para mi sorpresa (no exenta de vanidad, todo sea dicho), me propuso, con la anuencia de su maestro, que le supusiera un prólogo a la edición de su tesis doctoral, la que el lector tiene ahora en sus manos, acerca del derecho de reversión en la expropiación forzosa. Invitación que no tenía otra "causa", según imagino, que el haber escrito unas páginas, hace ya más de una década, sobre la figura de la reversión, en concreto, en el caso de las expropiaciones legislativas singulares, y en el que esbozaba una propuesta de entendimiento del fenómeno de la reversión de la que se ocupa Isabel Gallego, bien que para hacer de la misma blanco de su crítica, a partir, justamente, del que constituye el nervio de su concepción, la reversión como un supuesto de invalidez sobrevenida" [23]. 
gocio jurídico (causa de la obligación; causa de la prestación; causa del negocio jurídico), localizaba, en la expropiación forzosa, la causa del negocio jurídico en el acuerdo de necesidad de ocupación o causa expropiandi en sentido estricto, ponía en entredicho, al decir de Cano Campos, "el propio concepto de causa del que parte, pues si se acepta que la causa de los actos administrativos es «la adecuación del acto al fin que en cada caso ha de perseguirse con el dictado de aquél», parece evidente que el contenido del acto expropiatorio puede dejar de adecuarse al fin, y por tanto desaparecer de forma sobrevenida, cuando el fin de la expropiación ha sido realizado originariamente pero después ha desaparecido (el fin puede sufrir alteraciones), esto es, en el supuesto de la desafectación ulterior de los bienes y derechos" 23 .

C) El transcrito es un típico ejemplo de razonamiento circular: se afirma que la tesis criticada "pone en entredicho", vale decir es incoherente o inconsecuente, el propio postulado de que parte...la concepción propia, esto es, aquella que pretende oponerse, a modo de refutación, a la criticada. Supuesto que la causa venga definida por la adecuación o congruencia entre contenido y fin, en modo alguno puede "parece[r] evidente" que el contenido del acto en que consiste la expropiación forzosa "dej[e] de adecuarse al fin, y por tanto desaparecer de forma sobrevenida", justamente porque esta es la concepción de la que no se parte, antes bien, se excluye radicalmente. Naturalmente que la impugnación de la construcción montada sobre la noción que traduce el sintagma invalidez sobrevenida "supone partir de una concepción estática de la causa de los actos administrativos". No puede ser de otra manera: la causa y el contenido son los elementos (por seguir con el grafismo de nuestro autor) estáticos del acto administrativo (¿puede, lógica, ontológicamente, concebirse de otro modo la arquitectura, el entramado estructural, de un edificio, siquiera ideal como ocurre con el acto administrativo?; quizá, no, pero entonces el riesgo de...deslizamiento, con grave riesgo de su estabilidad, parece evidente). El fin, también conceptuado como elemento objetivo, trasciende de esta consideración en tan-

\footnotetext{
${ }^{23}$ La invalidez sobrevenida de los actos administrativos, 298. Y continúa:

"Sostener que esa adecuación sólo ha de darse en el momento previo de autorizar el ejercicio de la expropiación, momento en que la causa expropiandi agotaría sus efectos, supone partir de una concepción estática de la causa de los actos administrativos, pues se desconoce con ello que la adecuación del contenido del acto al fin que con el mismo ha de perseguirse (y que viene determinado por la norma atributiva de la potestad en ejercicio de la cual el acto se dicta) puede venir exigida por el ordenamiento no sólo en un momento inicial, sino también con posterioridad y de forma permanente. El ordenamiento puede disponer, en efecto, que la referida adecuación entre el contenido del acto y el fin normativo no sólo concurra ex ante, en el momento de iniciarse la expropiación, sino también ex post, durante un determinado período de tiempo (diez años por ejemplo) o durante todo el tiempo que sigue a la expropiación; que la causa, en definitiva, no sólo sea inicial, sino sucesiva o permanente" [298-99].
} 
to que componente (de aceptarse que a la expropiación forzosa, como en general a la construcción del acto administrativo, pueda aplicarse el canon de la teoría del negocio jurídico) metanegocial del acto administrativo ${ }^{24}$, de ahí que la causa no sea sino la ligazón entre el contenido del acto (su componente negocial en sentido estricto, esto es, la declaración en que consiste el acto como negocio jurídico) y el fin (elemento legal, no negocial), la razón de ser de aquel contenido, de su concreta extensión, y cuyo control se cumple necesariamente mediante la verificación (en términos de congruencia, razonabilidad o plausibilidad, según se prefiera) de la real concurrencia de las razones aducidas (la motivación ex artículo 54 LRJ-PAC) por la Administración al dictar, precisamente con el contenido específico que lo define, el acto administrativo de que se trate.

D) Esta es la razón última de la ubicación en el fin de la expropiación forzosa de la reversión: solamente la no realización de aquél, vale decir la frustración del fin que justifica la privación en que consiste la expropiación, permite dar cuenta del porqué ha de producirse (de ser material y legalmente posible, pero esto no afecta sustancialmente al desarrollo del argumento) la retrocesión de los bienes o derechos expropiados, esto es, la reintegración o restitución de las prestaciones anudadas a la expropiación forzosa (admitamos, una vez más, que le sea de aplicación el canon o formato del negocio jurídico), a saber, los derechos expropiados y el correspondiente justiprecio.

Una reintegración o restitución de las prestaciones que sólo puede explicarse lógicamente en términos de ineficacia (sobrevenida, por hipótesis), nunca en términos de validez: la expropiación forzosa nace, como negocio jurídico, plena y cumplidamente perfecto, en modo alguno aderezado con una condición resolutoria, a saber, la resolución de aquélla de no realizarse el fin que está en su base, que es su justificación jurídica (en el ámbito de las potestades administrativas, pero también en cualquier otro ámbito, público o privado, que quepa encuadrar en el molde de la teoría del negocio jurídico). Y ello porque, como se ha dejado dicho, el fin trasciende del propio nacimiento de la expropiación forzosa, dada su inexcusable apoyatura en la norma que es su sustento o cobertura (el artículo 9 de la Ley de Expropiación Forzosa, justamente). El fin, la ley, en definitiva, persigue asegurar la eficacia, esto es, la transformación del estado de cosas prexistente, de los actos para cuya emanación la Administra-

\footnotetext{
${ }^{24}$ No parece necesario insistir en este extremo: la predeterminación normativa del fin, consecuencia de su objetividad y tipicidad, le otorgan de manera inconcusa esta consideración de componente metanegocial del acto administrativo.
} 
ción, mediante el ejercicio de sus potestades, deviene habilitada, de suerte que, en esta lógica, la validez del acto no es, en términos sustanciales o materiales, sin un mero instrumento (recte: presupuesto) del fin (de su realización, de su eficacia, en suma) previsto en la norma y, desde un punto de vista formal (inherente al sometimiento a la ley y al derecho de toda la actividad administrativa), un prius del correcto proceder de la Administración Pública.

E) El colofón del razonamiento de Cano Campos es una mera reiteración de su punto de partida: "El ordenamiento puede disponer, en efecto, que la referida adecuación entre el contenido del acto y el fin normativo no sólo concurra ex ante, en el momento de iniciarse la expropiación, sino también ex post, durante un determinado período de tiempo (diez años por ejemplo) o durante todo el tiempo que sigue a la expropiación; que la causa, en definitiva, no sólo sea inicial, sino sucesiva o permanente" 25 . No creo que sea preciso añadir consideración alguna.

\section{RESUMEN:}

El texto analiza, al hilo de una concreta aportación doctrinal, la bondad de la teoría de la "invalidez sobrevenida" de los actos jurídicos. Como pórtico, se esboza una crítica de la llamada "inconstitucionalidad sobrevenida" (aplicación de la reseñada teoría a la cuestión del control de las leyes preconstitucionales), para, a continuación, esbozar un planteamiento diferente al que subyace a la meritada doctrina o teoría de la "invalidez sobrevenida". Un planteamiento que pasa por la distinción entre validez y eficacia como categorías jurídicas, y que hace pivotar el problema que la doctrina criticada articula como una cuestión de invalidez sobrevenida sobre la segunda de las categorías mencionadas, la eficacia, de suerte que la validez es concebida con un carácter sincrónico, esto es, anclada estrictamente en el momento del surgimiento a la vida jurídica del correspondiente acto jurídico (noción esta de carácter general, comprensiva de aquellas manifestaciones jurídicas que son producto de una declaración de voluntad, sea de carácter normativo o de índole meramente aplicativa, como ocurre con los actos administrativos), en tanto que la primera de las señaladas, la eficacia, tiene una dimensión diacrónica, que permite, justamente, dar cuenta de los avatares anudados, desde una perspectiva temporal, a los actos jurídicos. El trabajo aborda finalmente, como aplicación de la tesis esbozada, la cuestión de la reversión en la expropiación forzosa, que se explica, frente a la tesis dominante, a partir de la distinción entre el fin y la causa en

${ }^{25}$ La invalidez sobrevenida de los actos administrativos, 298-99. 
la expropiación forzosa, caracterizado aquél como el objeto o finalidad de utilidad pública o interés social que legitima la privación en que consiste la expropiación forzosa, en tanto que la causa, a saber, la causa expropiandi en sentido estricto, viene a identificarse con el acuerdo de necesidad de ocupación. En este sentido, por tanto, la reversión deja de ser la consecuencia de la desaparición (sobrevenida, obviamente) de la causa expropiandi para pasar a configurarse, estrictamente, como la frustración del fin de una concreta expropiación de bienes o derechos.

Palabras clave: Inconstitucionalidad sobrevenida; invalidez sobrevenida; validez; eficacia; fin; causa; expropiación forzosa; reversión. 